\title{
FRONTIERS
}

\section{Creative Accounting}

\section{Partha Dasgupta}

\section{It is only a matter of time before economics makes room for nature. The sooner the better.}

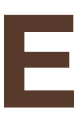
conomists, of course, might acknowledge nature's existence. But most deny its worth.

I have colleagues who believe that the services nature provides are responsible for just $2-3 \%$ of an economy's output. That is the same percentage that agriculture contributes to the US gross domestic product (GDP). Why, they ask, should a capital asset of negligible importance be incorporated into economic assessments of growth?

Economists assume that nature is a fixed, indestructible capital asset. They believe that, moreover, nature helps other forms of capital assets to thrive and that the GDP is capable of growing indefinitely thanks to the enduring power of human ingenuity to circumvent natural constraints to growth.

Economists also believe that the tremendous increase in population in the twentiieth century global population grew from 1.65 billion in 1900 to 6 billion in 2000 - need not constrain the quest to end poverty and create wealth in poor countries today.

The problem with the notion that nature is indestructible is this: it is wrong. Once economists accept that they are mistaken on this count, it could revolutionize the way in which we calculate economic progress - or the lack of thereof - especially in developing countries.

Nature consists of degradable resources (soil, watersheds, fisheries, fresh water, and the atmosphere). In the past, it might have been reasonable to think that nature was indestructible. That is because the demands we placed on nature were small compared to its size and bounty. But today's research tells us that this notion is no longer reasonable.

Economists regard nature as consisting of 'self-renewing assets'. By contrast, roads, buildings, and machinery are 'reproducible assets'. Economists agree both categories of assets will depreciate if misused or overused. Nevertheless nature's assets differ from reproducible assets in three important ways.

First, when nature depreciates, the result can be irreversible (or, at best, can take a very long time to recover). Second, it is not possible to replace a depleted or degraded ecosystem by a new one in the way that roads or machinery can be replaced. Third, ecosystems can collapse abruptly and without warning. Take the example of the Grand Banks on the eastern coast of the USA and Canada, which experienced a tipping point that led to a precipitous decline in fishing stocks in the 1980s, from which it still awaits recovery.

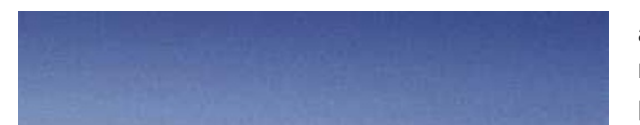

accounting for national income. That is because nature's services are weakly defined or underpriced. lit is also because nature's services are viewed as indestructible. The assumption is that nature, whose services are largely cost-free, will continue to operate forever without ever being harmed.

However, if we accept that water from aquifers, productive forests and coral reefs are resources that can decline or deteriorate, we will also need to accept that, when this occurs, we will need to pay potentially large sums to maintain the services that they provide us with.

There are additional reasons why economists need to account for natural capital. We know, for example, that an economy's productive base will shrink if its stock of natural capital assets depreciates and if human ingenuity and investment in reproducible capital cannot compensate for that loss.

National accounts, such as GDP, might still record economic progress under such circumstances. The reason is that GDP does not take into consideration the depreciation of natural capital. As a result, under current national assessments, an economy's productive base can decline even as per capita GDP grows. Crude estimates suggest that this might have happened in parts of sub-Saharan Africa over the past 30 years.

If the natural capital of an economy continues to shrink, standards of living will eventually decline. Rising GDP, however, will mask what is happening. Indeed it will suggest that all is well. National statistics, in short, paint a distorted picture of the state of the economy.

The study of possible feedback loops between poverty, population growth, and the character and performance of both human institutions and natural capital, unfortunately, is not yet on the research agenda of economists. This might be why 'ecological economics' remains isolated from the main body of economics.

We can no longer afford to engage in a gross accounting of economic growth, whether that accounting is taking place at the local or global level. We need instead to develop a true accounting that acknowledges - and incorporates - nature's significant but hidden assets. The consequences are important for the future of our global community, and even more important for the future of the developing world.

Partha S. Dasgupta (TWAS Fellow 2001) is the Frank Ramsey professor of economics at the University of Cambridge in London, UK. 